\title{
Atlas condemned to hold up the celestial heavens and bailout the mechanical thrombectomy failures in stroke?
}

\author{
Atlas condenado a segurar os céus e resgatar falhas da trombectomia mecânica no \\ acidente vascular cerebral isquêmico?
}

Igor PAGIOLA ${ }^{1,2,3}$, Michel Eli FRUDIT2,4, José Guilherme Mendes Pereira CALDAS5,6

Despite the efficacy (70-80\%) of large vessel occlusion (LVO) strokes mechanical thrombectomy (MT) ${ }^{1}$, some cases do not result in recanalization. Major causes of MT failure is mainly due to intracranial atherosclerotic disease ${ }^{2}$, but there are other reasons such as fibrin-rich clots and calcified thrombi ${ }^{3}$.

If calcified thrombus signals (Figure 1) associated with MT technique fail, bailout stenting with permanent placement of a self-expanding stent should be considered $^{4,5}$.
The safety and efficacy of this rescue technique have already been described.

We placed one laser cut stent (Figures 2 and 3) after 3 attempts of MT (SOLUMBRA technique and balloon guiding catheter) with a final thrombolysis in cerebral infarction (TICI) 2a. Patient was discharged from the hospital with National Institutes of Health Stroke Scale (NIHSS) of 17, and 30 days image follow-up is demonstrated in Figure 4.
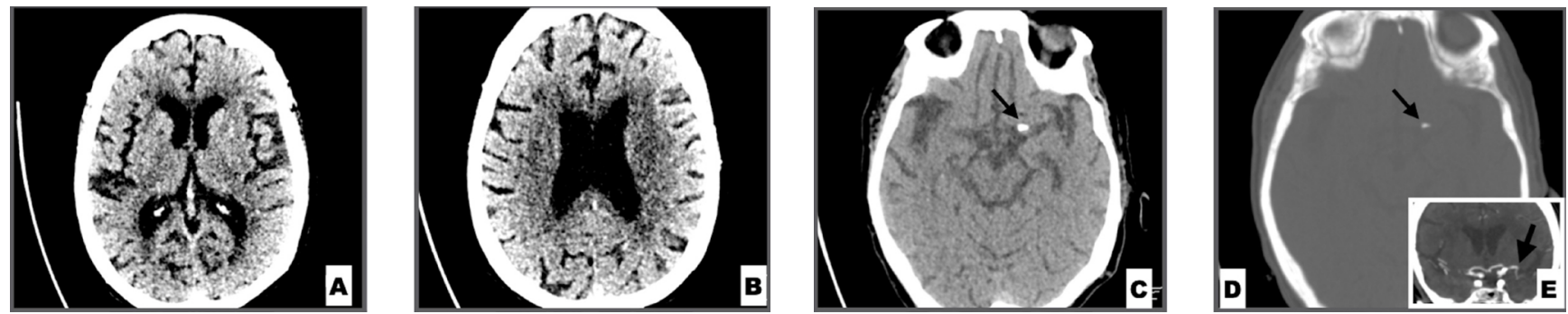

Figure 1. (A) Non-contrast brain computed tomography basal ganglial level; (B) non-contrast brain computed tomography corona radiate level; (C) non-contrast computed tomography demonstrates a calcified clot in the left M1 segment (arrow); (D) computed tomography head bone window with the calcified clot in the left M1 segment (arrow); (E) internal carotid artery with left M1 occlusion (arrow).

\footnotetext{
'Universidade Federal de São Paulo, Disciplina de Neurorradiologia Intervencionista, São Paulo SP, Brazil.

${ }^{2}$ Hospital Sírio-Libanês, Neurorradiologia Intervencionista, São Paulo SP, Brazil.

${ }^{3}$ Hospital Estadual Central, Disciplina de Neurorradiologia Intervencionista, Vitória ES, Brazil.

${ }^{4}$ Universidade Federal de São Paulo, Disciplina de Neurorradiologia Intervencionista, São Paulo SP, Brazil.

5Universidade de São Paulo, Faculdade de Medicina, Disciplina de Neurorradiologia Intervencionista, São Paulo SP, Brazil.

${ }^{6}$ Hospital Sírio-Libanês, Setor de Neurorradiologia Intervencionista, São Paulo SP, Brazil.

Igor PAGIOLA (iD https://orcid.org/0000-0001-9052-7946; Michel Eli FRUDIT (DD https://orcid.org/0000-0003-3882-0226;

José Guilherme Mendes Pereira CALDAS (D) https://orcid.org/0000-0002-1916-7121

Correspondence: Igor Pagiola; E-mail: igorpagiola@hotmail.com

Conflict of interest: There is no conflict of interest to declare.

Authors' contributions: All authors contributed equally to this work.

Received on June 17, 2020; Received in its final form on August 22, 2020; Accepted on August 24, 2020.
} 

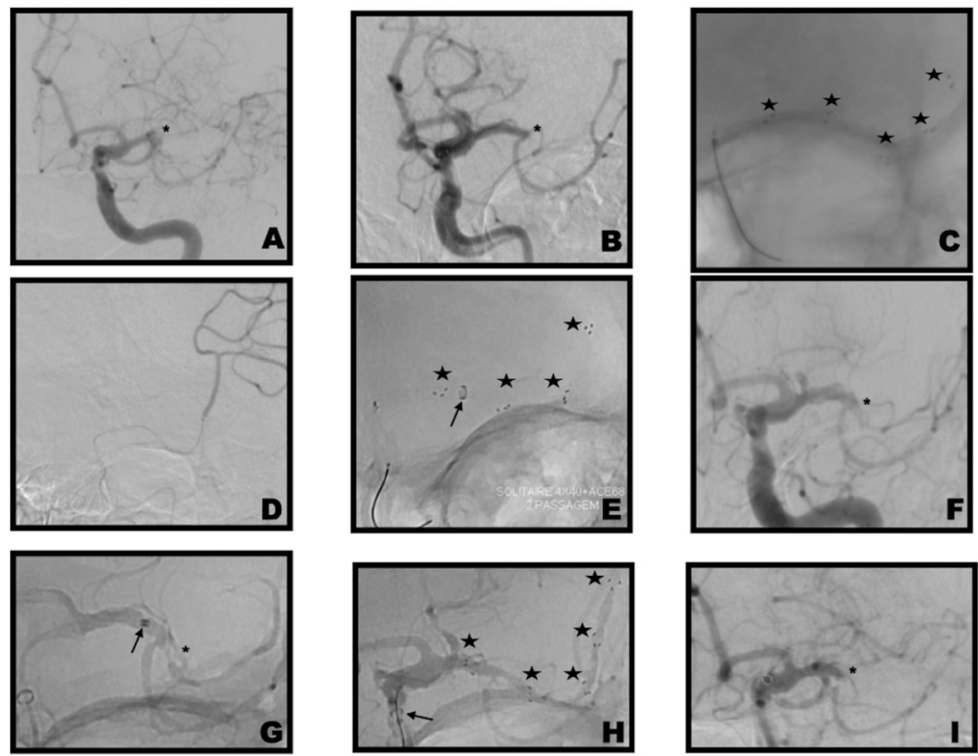

Figure 2. (A) Left internal carotid artery DSA image in the anteriorposterior projection shows the proximal occlusion of the left M1 segment; (B) DSA image after the first pass mechanical thrombectomy (SOLUMBRA technique) with TICl 0, asterisk in the occlusion site; (C) non subtraction image from the left internal carotid artery with a $4 \times 40 \mathrm{~mm}$ Solitaire platinum Stent retriever (ev3/Covidien, Irvine, CA, USA) with the typical 3 radiopaque markers in each 10 mm (Stars); (D) Rebar 18 (ev3/Covidien, Irvine, CA, USA) microcatheter DSA image; (E) second pass non subtraction image from the left internal carotid artery with a $4 \times 40 \mathrm{~mm}$ Solitaire platinum Stent retriever (ev3/Covidien, Irvine, CA, USA) with the typical 3 radiopaque markers in each $10 \mathrm{~mm}$ (Stars) and the large bore aspiration catheter ACE 68 (arrow) (Penumbra, Alameda, California, USA); (F) DSA image after the second pass mechanical thrombectomy (SOLUMBRA technique) with TICI 0, asterisk in the occlusion site; (G) Marksmann (ev3/Covidien, Irvine, CA, USA) microcatheter DSA image near the occlusion (asterisk); $(H)$ third pass non subtraction image from the left internal carotid artery with a $4 \times 40 \mathrm{~mm}$ Solitaire platinum Stent retriever (ev3/Covidien, Irvine, CA, USA) with the typical 3 radiopaque markers in each $10 \mathrm{~mm}$ (Stars) and the large bore aspiration catheter ACE 68 (arrow) (Penumbra, Alameda, California, USA) before the ACEC 68 approach to the clot; (I) DSA image after the third pass mechanical thrombectomy (SOLUMBRA technique) with TICI 0. Asterisk in the occlusion site.
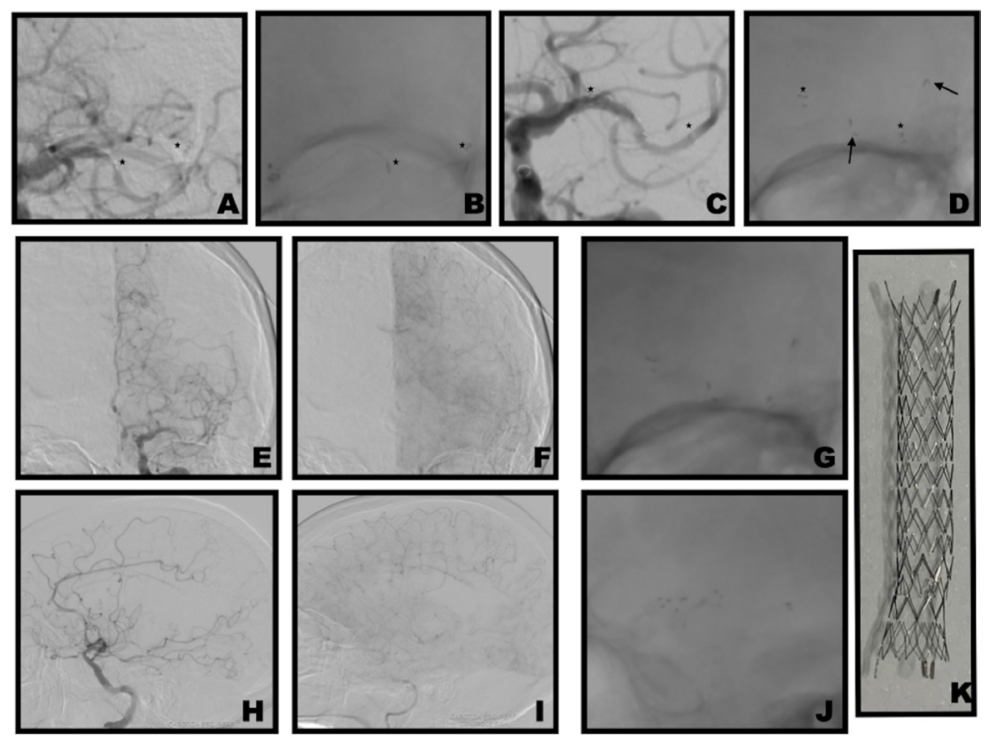

Figure 3. (A) $3 \times 24$ mm Neuroform Altas (Stryker Neurovascular, Fremont, California, USA) beyond the occlusion site; Stars in the radiopaque markers of the Stent. (B) Non subtraction image with the first Neuroform Altas ( $3 \times 24 \mathrm{~mm}$ ); Stars in the radiopaque markers of the Stent. (C) Second Neuroform Atlas $(3 \times 21 \mathrm{~mm})$ in the right position; Stars in the radiopaque markers of the Stent. (D) Non subtraction image with both Neuroform Atlas Stents ( $3 \times 24 \mathrm{~mm}$ - arrows in the radiopaque markers; $3 \times 21 \mathrm{~mm}-\mathrm{Stars}$ ). (E) Left internal carotid artery DSA AP image after the bailout stenting rescue technique with a TICI 2a result. (F) Late arterial phase of the left internal carotid artery DSA AP image after the bailout stenting rescue technique with a TICI 2a result; (G) AP non subtraction image. $(\mathrm{H})$ Left internal carotid artery DSA lateral image after the bailout stenting rescue technique with a TICI $2 \mathrm{a}$ result. (I) Late arterial phase of the internal carotid artery DSA lateral image after the bailout stenting rescue technique with a $\mathrm{TICl} 2$ a result. (J) Lateral non subtraction image. (K) Neuroform Atlas (Stryker Neurovascular, Fremont, California, USA): laser-cut self-expanding, open-cell, nitinol Stent. 


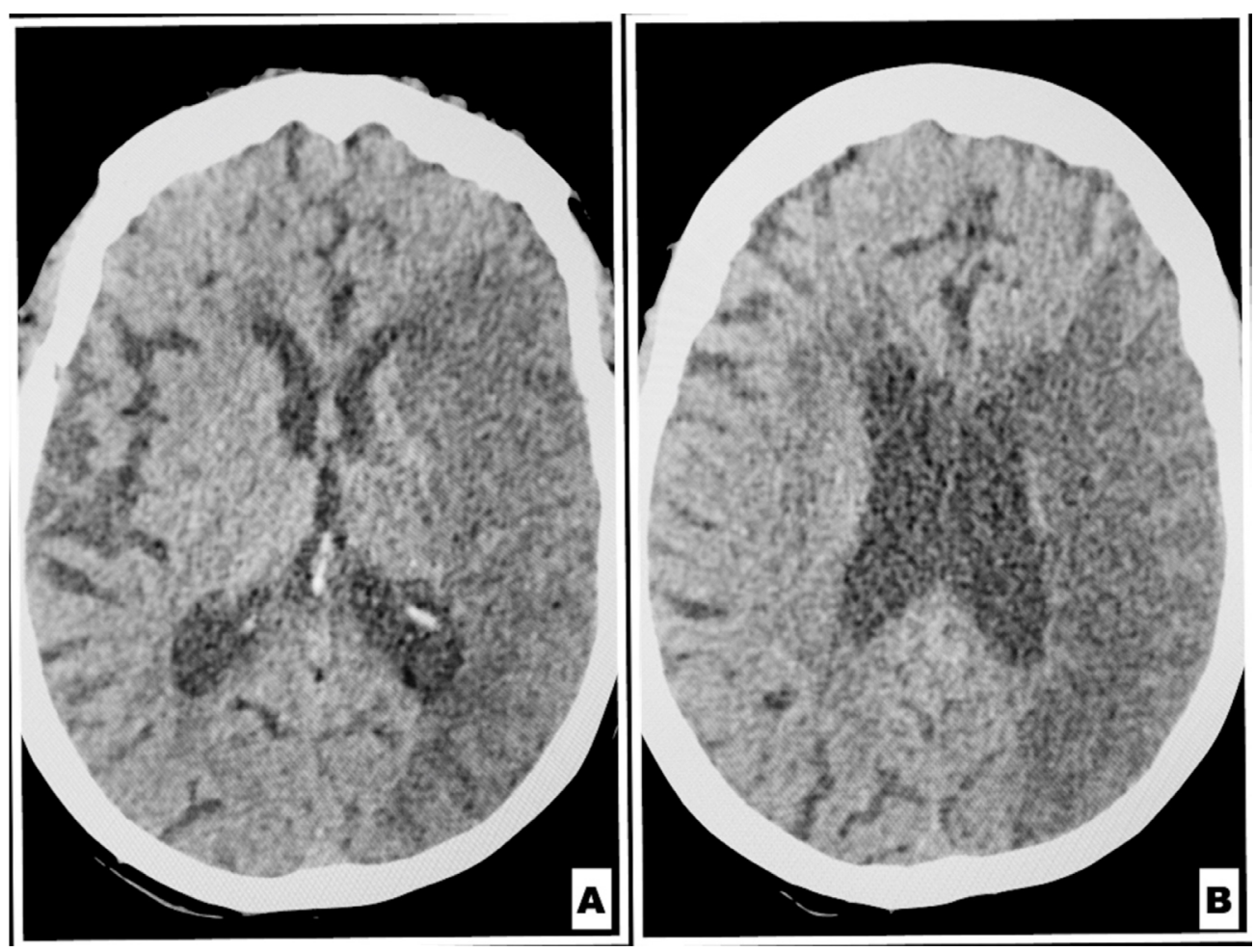

Figure 4. (A) 30 days follow-up non contrast brain computed tomography basal ganglial level; (B) 30 days follow-up non contrast brain CT corona radiata level. (B) 30 days follow-up non contrast brain CT corona radiata level.

\section{References}

1. Goyal M, Menon BK, Van Zwam WH, Dippel DWJ, Mitchell PJ, Demchuk AM, et al. Endovascular thrombectomy after large vessel ischaemic stroke: a meta-analysis of individual patient data from five randomised trials. Lancet. 2016 Apr;387(10029):1723-31. https://doi.org/10.1016/S0140-6736(16)00163-X

2. Jia B, Feng L, Liebeskind DS, Huo X, Gao F, Ma N, et al. Mechanical thrombectomy and rescue therapy for intracranial large artery occlusion with underlying atherosclerosis. J Neurointerv Surg. 2018 Aug;10(8):746-50. https://doi.org/10.1136/neurintsurg-2017-013489

3. Dobrocky T, Piechowiak E, Cianfoni A, Zibold F, Roccatagliata L, Mosimann P, et al. Thrombectomy of calcified emboli in stroke. Does histology of thrombi influence the effectiveness of thrombectomy?
J Neurointerv Surg. 2018 Apr;10(4):345-50. https://doi.org/10.1136/ neurintsurg-2017-013226

4. Stracke CP, Meyer L, Fiehler J, Leischner H, Bester M, Buhk JH, et al. Intracranial bailout stenting with the Acclino (Flex) Stent/ NeuroSpeed Balloon Catheter after failed thrombectomy in acute ischemic stroke: a multicenter experience.J Neurointerv Surg. 2020 Jan;12(1):43-7. https://doi.org/10.1136/neurintsurg-2019-014957

5. Peng F, Wan J, Liu W, Huang W, Wang L, Qiu T, et al. Efficacy and safety of rescue stenting following failed mechanical thrombectomy for anterior circulation large vessel occlusion: propensity score analysis. J Neurointerv Surg. 2020 Mar;12(3):271-3. https://doi. org/10.1136/neurintsurg-2019-015154 